\title{
German National Guideline on the management of pilonidal disease: update 2020
}

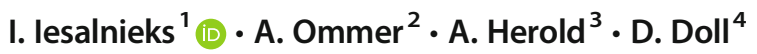 \\ Received: 13 November 2020 / Accepted: 14 December 2020 / Published online: 5 May 2021 \\ (C) The Author(s), under exclusive licence to Springer-Verlag GmbH Germany, part of Springer Nature 2021
}

\begin{abstract}
Background The present German National Guideline is an updated version of previous Guideline published in 2014. It aims to compare various treatment methods and to assist physicians with evidence-based recommendations.

Methods Systemic literature review.

Results Three types of disease manifestation could be differentiated: asymptomatic disease, an acute abscess, and the chronic pilonidal disease. At present, there is no treatment method fulfilling all desired criteria: simple, painless procedure associated with rapid wound healing, and low recurrence rate. Thus, treatment modality should be tailored to disease manifestation and extent. Conclusion Asymptomatic pilonidal disease should not be treated. A pilonidal abscess should be unroofed. After resolution of the acute inflammation, the disease should be treated definitely. As for today, sinus excision is the standard treatment of the chronic pilonidal disease. Wide excision and open treatment of chronic disease is a safe procedure which, however, leads to prolonged secondary healing and time off-work, as well as to considerable recurrence rate. The extent of excision should be as limited as possible. Excision and midline wound closure is associated with impaired outcomes. Today, it has become obsolete. Minimally invasive procedures (e.g., pit picking surgery) represent a treatment option for chronic pilonidal disease. However, the recurrence rate is higher compared to excision procedures. Nevertheless, they may be used for small primary disease. Off-midline procedures should be used for disease not suitable for minimally invasive treatments. The Limberg flap and the Karydakis procedure are two best described methods which are associated with similar short- and long-term results.
\end{abstract}

Keywords Pilonidals sinus $\cdot$ Pilonidal disease $\cdot$ Pilonidal abscess $\cdot$ Surgery

\section{Introduction}

In 2014, German National Guideline on the Management of Pilonidal disease was published first in German and 2017 in English language [1]. Since then, there has been an ongoing research on pathogenesis and treatment of pilonidal disease worldwide. In the recent decade, minimally invasive methods like endoscopic and laser treatments emerged and gained

I. Iesalnieks

iesalnieks_igors@hotmail.com

1 Dept. of Surgery, München Klinik Bogenhausen, Englschalkinger Str. 77, 81925 Munich, Germany

2 End- und Dickdarm-Zentrum Essen, Essen, Germany

3 End- und Dickdarmzentrum Mannheim, Mannheim, Germany

4 Dept. of Procto-Surgery, St. Marienhospital Vechta, Vechta, Germany some popularity. Moreover, the use of laser procedures to prevent postoperative recurrences has been described. Also, numerous publications and reviews on off-midline procedures increased the quality of the overall body of evidence. Nevertheless, traditional midline excision is still widely used in most countries. This article represents an updated consensus review of pilonidal disease management based on best current evidence. Find the summary of recommendations of the current Guideline Update in Appendix.

\section{Methods}

Starting from previous Guideline published in German language 2014, the authors identified topics for inclusion. All invited authors accepted participation and received instructions for the literature search. PubMed and Cochrane databases were used to identify relevant contributions from April 2014 (end date of the search for the previous Guideline version) and May 2019. 
Medical Subject Headings terms were used, as were accompanying entry terms for patient group, interventions, and outcomes. Key words included "pilonidal*," "sinus," and "201*." Searches were limited to studies published in English and German languages and focusing on human subjects. Titles and abstracts were screened by individual reviewers to identify potentially relevant articles. Thereafter, full publications were read by three principal reviewers (I.I., D.D. and A.O). Relevant papers in German language published in journals not listed in the MEDLINE Database after 2013 were included, because the Guideline was mainly aimed on medical providers in countries with German language.

Levels of evidence were assessed according to criteria developed by Centre for Evidence-Based Medicine, Oxford, UK [2] for therapy/prevention/etiology/harm questions and using GRADE criteria [3]. The Graduation of Recommendations is illustrated by Fig. 1 and Table 1. Due to COVID-19 pandemic, no consensus meeting was held. The conclusions of the current Guideline were sent by e-mail to all members of Guideline committee, and responses to Delphi method questionnaire were recorded. The Guideline committee consisted of representatives from specialist societies involved in treatment of pilonidal disease: surgical societies (Deutsche Gesellschaft der Koloproktologie, DGK; Berufsverband der Coloproktologen Deutschlands, BCD; Chirurgische Arbeitsgemeinschaft für Coloproktologie, CACP; Deutsche Gesellschaft für Allgemein- und Viszeralchirurgie, DGAV), the dermatological society (Deutsche Dermatologische Gesellschaft), and the gastroenterologist society (Deutsche Gesellschaft für Verdauungs- und Stoffwechselkrankheiten). The strength of the consensus was defined as demonstrated in Table 2. Current Guideline update had been pre-published 2020 [4] in German language in coloproctology. However, it did not appear in any PUBMED-cited journal previously. The present manuscript is a shortened English version of the current update; thus, its content was held as close as possible to the German version. The preparation of the present Guideline was assisted by the Association of the Scientific Medical Societies in Germany (Arbeitsgemeinschaft der Wissenschaftlichen Medizinischen Fachgesellschaften, AWMF). AWMF represents Germany in the Council for International Organizations of Medical Sciences CIOMS and is authorized to issue national guidelines.

Table 1 Diagram illustrating classification of recommendation

\begin{tabular}{lll}
\hline $\begin{array}{l}\text { Grade of } \\
\text { recommendation }\end{array}$ & Description & Syntax \\
\hline A & Strong recommendation & Shall/shall not be done \\
B & Recommendation & Should/should not be done \\
0 & Recommendation open & Can be considered \\
\hline
\end{tabular}

Table 2 Definition of consensus strength

\begin{tabular}{ll}
\hline Strong consensus & Consent by $>95 \%$ of meeting participants \\
Consensus & Consent by $75-95 \%$ of meeting participants \\
Majority agreement & Consent by $50-75 \%$ of meeting participants \\
No consensus & Consent by $<50 \%$ of meeting participants \\
\hline
\end{tabular}

\section{Asymptomatic disease}

No principal changes to the previous version of Guideline have been done. Surgery for asymptomatic disease is not recommended [5]. No spontaneous disease progression had been observed in an observational study [6]. In contrast, a complete spontaneous remission of symptomatic disease is unlikely. Thus, surgery is indicated for symptomatic cases.

\section{Summary and recommendations}

There is no indication for prophylactic treatment in patients with asymptomatic disease. In contrast, symptomatic disease can be cured only by surgery. Timing of intervention is dictated depending on whether an acute abscess or chronic disease is present. For diagnostic purposes, only patients' history and physical examination are implied.

Level of evidence: low

Consensus strength: strong consensus

\section{Acute abscess}

Incision and drainage (I+D) is indicated in most cases of acute pilonidal abscess, although needle aspiration followed by antibiotics has been described by some authors [7, 8]. Long-term recurrence-free healing can occur following I+D [9]. In the previous version of this Guideline, definitive excision was recommended as an alternative to simple $\mathrm{I}+\mathrm{D}$ in case of small abscesses. However, in the present version, I+D is the preferred method for all acute abscesses.

\section{Summary and recommendations}

Incision and drainage is indicated in most patients with pilonidal abscess. Elective surgery should be performed after resolution of acute inflammation.

Level of evidence: middle

Consensus strength: consensus

\section{Phenol treatment}

Favorable results following minimally invasive phenol treatment have been described previously [10-17]. Recently, Calikoglu et al. [18] demonstrated similar long-term recurrence rate (23\% vs. $15 \%$ after 4 years) and significantly 


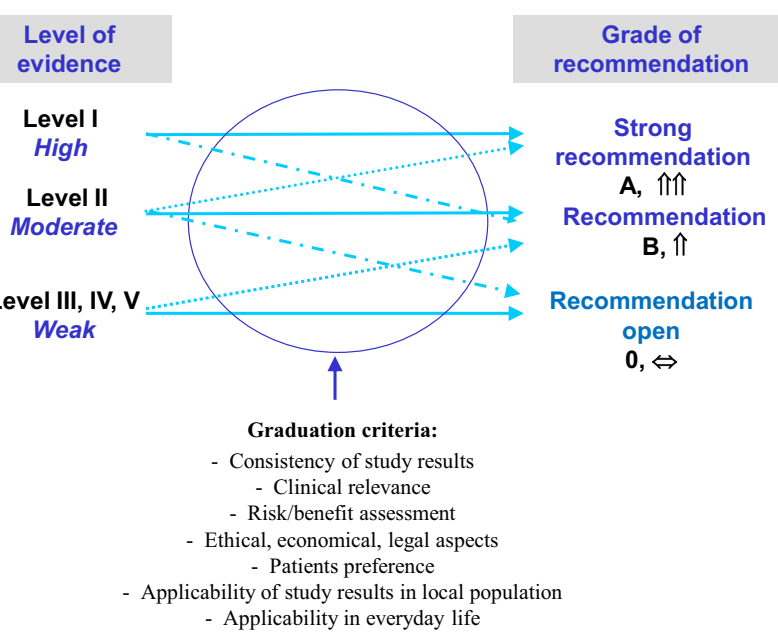

Fig. 1 Transformation process from level of evidence to grade of recommendation. Recommendations are based not only on level of evidence of available studies but also on preferences, applicability, cultural traditions, values, etc.

shorter sick leave after crystallized phenol injection as compared with open excision in a prospective randomized trial including 140 patients. Yet, due to its presumed toxicity [19], treatment by phenol is not allowed by German health authorities. Thus, the final statement stays unchanged to the previous version of the Guideline.

\section{Summary and recommendations}

Despite favorable results in recent studies, the human use of phenol has been banned by German health authorities due to its toxicity.

Level of evidence: high

Consensus strength: strong consensus

\section{Pit picking and similar procedures}

There are numerous variations of minimally invasive techniques to treat pilonidal disease. Also, different names are used. However, principal steps are common in most descriptions which include minimal excision of midline pits and some type of cleansing or drainage of the secondary tracks and cavities [20-23]. Gips et al. [24] used trephines instead of knife and cleaned the underlying cavity more intensively. The latter study is one of the most often cited publications on minimally invasive pilonidal treatment without use of laser or endoscopes. The main advantage of pit picking [21, 23] and all other minimally invasive techniques is minimal pain and short time out of work.

The recurrence rate following pit picking and similar procedures is expected to be $8-26 \%$ between 12 and 120 months after surgery; however, there are various definitions of recurrence following minimal procedures making comparisons between studies difficult. In a recent retrospective study by
Khodakaram et al., 241 patients [25] were treated either by open healing or by a "modified Lord-Millar" procedure which is predecessor of the pit picking surgery. Authors reported on $23 \%$ recurrence rate 3 years after the modified LordMillar procedure. The results were comparable between both methods. The only prospective randomized study was conducted by Nordon [22] and compared pit picking (which was called "simple Bascom technique" in that publication) to cleft lift. The recurrence rate was $24 \%$ after 36 months in the pit picking group.

\section{Summary and recommendations}

Pit picking and its variations should be used in previously untreated patients with minimal disease. There is still lack of reliable long-term results.

Level of evidence: middle

Consensus strength: strong consensus

Grade of recommendation: B

\section{Sinusectomy}

Sinusectomy was first described by Soll et al. 2008 [26] as "limited excision." The method was named "sinusectomy" by same authors in their follow-up study 2011 [27]. The midline pits and sinus are closely excised with the scalpel or scissor following the dye-marked track. Sinusectomy is performed under local anesthesia in most cases [27]. The main difference to pit picking and its variations is a complete (subcutaneous) excision of the sinus tract. The main difference to the traditional excision surgery is a close tracing of the tract instead of wide excision. Since the first description of the method 2008, there are few additional studies and no one since publication of the previous version of the Guideline [28-31].

The reported recurrence rates after a follow-up period of 20 to 43 months are $1.6-7 \%$. The method is limited to patients with less than 3 pits. Two prospective randomized studies [29, 31] compared sinusectomy ("sinus excision") to traditional excision with or without marsupialization. The recurrence rate after sinusectomy was $0 \%$ after 10 months in one [29] and 3\% after > 15 months in another [31] study.

\section{Summary and recommendations}

Sinusectomy can be considered as a minimally invasive procedure for treatment of locally limited pilonidal disease. However, there is still a considerable scarcity of data to draw definite conclusions.

Level of evidence: high

Consensus strength: strong consensus 


\section{Laying open procedure (unroofing)}

This method was not included in previous version of the Guideline. At surgery, a probe or a forceps is placed into the fistula tract and the latter cut open without complete excision. An additional curettage may be added. The wound is left open to heal; however, it is considerably narrower than after wide excision. Thus, the surgery can be done as an outpatient procedure.

A meta-analysis by Garg et al. [32], including 13 retrospective series, demonstrated a $4.5 \%$ recurrence rate, a healing time of 21-72 days and time out of work of 8 days. Unfortunately, in 5 of included studies, marsupialization has been used, thus hampering the final conclusions.

\section{Summary and recommendations}

Due to lack of reliable data, no formal recommendation can be given for laying open procedure.

Level of evidence: low

Consensus strength: strong consensus

\section{Endoscopic treatment}

Endoscopic treatment was not discussed in the previous version of the Guideline. During the recent decade, numerous publications demonstrated the technical feasibility and favorable short-term results of endoscopic treatment. The technique of the method includes minimal excision of the midline pits and video-assisted cleansing of the subcutaneous tracts. The advantage of the method, at least the theoretical one, is the fact that the tracts are treated under vision in contrast to pit picking or laser treatment. The method is best known as EPSiT (endoscopic pilonidal sinus treatment) [33-37]. In the study by Milone et al. [37], 145 previously untreated patients were randomly assigned either to EPSiT or cleft lift. There was prolonged time out of work in cleft lift group, whereas 1year recurrence rate (3\%) and infectious complications were similar in both groups. Four years later, the follow-up study does not have been published yet.

Two systemic meta-analyses [38, 39] including 497 patients, demonstrated treatment failure of only $8 \%$ (recurrences in $4 \%$ and persistent disease in $4 \%$ ), the average time out of work of 3 days, and healing time of 33 days following endoscopic treatment. However, the Guideline committee criticized the fact that most evidence is arising from only few centers. Thus, present evidence does not justify higher costs as compared with simpler minimally invasive methods.

\section{Summary and recommendations}

Due to lack of reliable data, no formal recommendation can be given for endoscopic treatment.
Level of evidence: high

Consensus strength: strong consensus

\section{Laser treatment}

Laser treatment represents another minimally invasive method which was introduced into the Guideline for the first time. Again, midline pits are excised with a small amount of skin and the most distal part of the fistula tract is opened. Thereafter, a radial fiber delivering laser energy is introduced into the sinus tract which is cleaned and sealed by withdrawing the fiber. There are several names for the procedure, most popular of which are PiLaT (pilonidal laser treatment) [40] and Silac [41]. Some retrospective series reported on $90 \%$ healing rates after laser procedures; however, there are no prospective randomized comparisons with other minimally invasive procedures. Pappas et al. [41] demonstrated healing rate of $78 \%$ after multiple laser procedures in 237 patients previously treated by other methods after 1 year of follow-up.

\section{Summary and recommendations}

Due to lack of reliable data, no formal recommendation can be given for laser treatment.

Level of evidence: low

Consensus strength: strong consensus

\section{Excision and open wound healing}

Despite increasing use of minimally invasive and off-midline procedures, the open healing is still the method most frequently used worldwide and also in Germany. The main drawbacks of the method are prolonged wound healing and time out of work. The wide discrepancies in reported recurrence rates from as low as $2-6 \%$ [42-48] to 15-35\% [49-57] are likely caused by different patient selection and recurrence definitions. The recurrence rate is particularly high in patients undergoing excision and open healing for recurrent disease. It was $20 \%$ after 20 years in one study [58], but as high as $42 \%$ in another [59].

After open healing, a proportion of patients develops chronic midline wound. Repeat surgery can lead to even larger non-healing wound, especially, when open healing is used again. A disabling long-standing disease can result. Unfortunately, exact incidence of chronic postoperative wounds after excision and open healing is not known. It was at least $6 \%$ in one prospectively randomized study [60].

Numerous randomized studies [49, 61-63] have been conducted to compare open healing with midline closure. Most studies - except one [49] — failed to demonstrate a significant difference in recurrence rates between both methods; however, the healing time was significantly prolonged in open healing [64]. Open healing was compared with Limberg flap 
in two prospectively randomized trials showing an increased recurrence rate after open healing in one (33\% vs. 4\%) [53] but not in another [60]. In a meta-analysis by Stauffer et al. [65] including more than 89,000 patients, the 10 -year recurrence rate was $20 \%$ after open healing, $2 \%$ after Karydakis flap, and $11 \%$ after Limberg flap.

\section{Summary and recommendations}

Wide excision and open healing is a simple treatment. Excision should be tailored to the extent of disease and stay as limited as possible. However, according to actual metaanalyses, main drawbacks are prolonged wound healing and time out of work, and an increased recurrence rate as compared with off-midline procedures*.

Level of evidence: high

Grade of recommendation: 0

Consensus strength: strong consensus

* German Dermatological Society (Deutsche Dermatologische Gesellschaft, DDG) did not agree with that particular conclusion. According to DDG, the meta-analysis by Stauffer et al. [65] does not provide sufficient evidence for an increased recurrence rate after wide excision.

\section{Marsupialization}

Little has been added to the body of evidence since the publication of the last version of the Guideline. Excision and marsupialization of the wound was associated with shorter healing time (3-4 weeks) $[66,67]$ and shorter time off-work (0.5-1.5 months) $[45,59,68]$ than open healing without marsupialization in older studies. Reported recurrence rates were as low as $0-10 \%[45,59,68]$. In a retrospective study by Doll et al. published 2015, patients reported to be less satisfied after marsupialization as compared with other surgical techniques 7 to 28 years after pilonidal surgery [69].

\section{Summary and recommendations}

Due to lack of reliable data, no formal recommendation can be given for marsupialization.

Level of evidence: low

Consensus strength: strong consensus

\section{Midline closure}

After excision and midline wound closure, a considerable incidence of wound dehiscence ranging between 14 and $74 \%$ $[47,70-80]$ has been frequently described and confirmed by recent randomized trials which compared midline closure to Limberg flap [70, 78, 81-83]. Also, a significantly increased recurrence rate after midline closure as compared with Limberg flap (4-45\% vs. $0-4 \%$ ) was demonstrated by latter studies 6 to 46 months following surgery. Consequently, a meta-analysis by $\mathrm{Al}$ Khamis et al. recommended to abandon the midline closure due to frequent wound problems and increased recurrence rate [64].

A tension-free midline closure has been described by some authors previously [84] and, recently, by Sevinc et al. [85] and Youssef [86]. The technique includes a subcutaneous release at the level of fascia of gluteus maximus muscle as wide as 3$5 \mathrm{~cm}$ leading to flattening of the wound after midline closure. The recurrence rates after 24 months were $6 \%$ in the Limberg and Karydakis groups and $4 \%$ in the tension-free primary closure group in the randomized study by Sevinc et al. [85].

\section{Summary and recommendations}

Midline closure should not be used due to high incidence of wound dehiscence and an increased recurrence rate.

Level of evidence: high

Consensus strength: strong consensus

Grade of recommendation: A

\section{Z-Plasty, V-Y flap, and Dufourmentel flap}

No additional evidence on V-Y-flap [87, 88], Z-plasty [89, 90], and Dufourmentel flap [91, 92] has been added since publication of the previous version of the Guideline. The reported results are similar to that after Karydakis flap, Limberg flap, and Cleft lift. However, these methods did not gain wide acceptance. Almost all reports are older retrospective series.

\section{Summary and recommendations}

Rarely used off-midline procedures play only a limited role in Germany. Thus, they cannot be recommended.

Level of evidence: low

Consensus strength: strong consensus

\section{Karydakis flap}

During the last 15-20 years, studies addressing Karydakis flap reported on recurrence rates between 0 and $6 \%$ after 10 years, wound dehiscence rates between 8 and $23 \%$, time out of work of 2-3 weeks, and hospital stay of 0-3 days [93-99]. In a meta-analysis by Prassas et al. $[100,101]$ including several prospective randomized trials, similar wound healing and recurrence rate were documented for Karydakis and Limberg flap with less seroma formation following the latter. In 2010, Cochrane review found a "clear benefit in favor of off-midline rather than midline closure, which should be the standard management when closures of sinuses is desired" [64]. 


\section{Summary and recommendations}

Karydakis flap should be considered as one of preferred offmidline procedures.

Level of evidence: high

Consensus strength: strong consensus

\section{Cleft-lift procedure}

There were no substantially new findings regarding cleft lift procedure since the publication of the Guideline 2014. The technique was developed by J. Bascom as a modification of the Karydakis flap during the early 1980s; however, it is still not widely used despite of encouraging results even in most difficult cases [102]. The reason for hesitant adoption of cleft lift lies probably in difficulties to understand how exactly the incision line is drawn. Similarly to Karydakis flap, recurrence rate is low- 0 to $5 \%$ after 10 years - despite of negative patient selection [103, 104]. The wound dehiscence which is caused mainly by infection of subcutaneous seroma is a frequent occurrence (15-40\%). However, that high incidence of wound problems might be as well caused by high proportion of recurrent cases in study populations. In only randomized trial, Nordon et al. [22] demonstrated significantly lower recurrence rate following cleft lift as compared with pit picking 13 months after surgery (0\% vs. $24 \%$ ).

\section{Summary and recommendations}

Cleft lift should be considered as one of preferred off-midline procedures. Main drawbacks of the procedure are difficulties to understand the marking and a trend towards an increased rate of wound complications.

Level of evidence: low

Consensus strength: strong consensus

\section{Limberg flap}

Limberg flap is the best described off-midline procedure to treat pilonidal disease including several randomized trials [82, 105-114]. In its original form, Limberg flap leads to crossing of the wound and the natal cleft which is the frequent point of non-healing wound dehiscences. Therefore, the "modified" Limberg flap was developed to achieve a complete lateralization of the postoperative wound. Accordingly, in studies comparing original technique to the modified one, the latter is associated with the lower rate of recurrences and wound complications [106, 107, 115]. Numerous [70, 78, 81, 82, 111, $114,116]$ randomized studies compared Limberg flap to midline closure or open healing reporting on better results after Limberg flap. In two recent meta-analyses [117, 118], Limberg flap along with Karydakis flap was proposed to be the first choice when non-minimally invasive methods are intended.

\section{Summary and recommendations}

Limberg flap should be considered as one of preferred offmidline procedures. The modified technique should be used instead of the original one in order to avoid postoperative wound crossing the midline.

Level of evidence: high

Consensus strength: strong consensus

\section{Fibrin glue}

The use of the fibrin glue was not discussed in the previous version of the Guideline. Authors of some recent studies used fibrin glue mostly in conjunction with some type of minimal excision of midline pits [119-121]. In a retrospective study by Sian et al. including 146 patients undergoing mere curettage of sinus tracts followed by fibrin glue application, a healing rate of $96 \%$ could be achieved after at least two fibrin treatments: encouraging results given the low invasiveness of the procedure [122]!

\section{Summary and recommendations}

Due to lack of reliable data, no formal recommendation can be given for fibrin glue treatment.

Level of evidence: low.

Consensus strength: strong consensus.

\section{Autologous tissue treatment}

The use of platelet-rich plasma or autologous adipose tissue as adjunction to some type of pilonidal treatment, mostly to midline or off-midline closure, has been described by some authors recently $[46,123,124]$. Reduced postoperative pain and faster wound healing has been described; however, any advantages in recurrence rate have not been reported as for today.

\section{Summary and recommendations}

Due to lack of reliable data, no formal recommendation can be given for autologous tissue treatments.

Level of evidence: low

Consensus strength: strong consensus

\section{Postoperative drainage use}

The benefit of placing subcutaneous drainage is still matter of controversial discussions. In two studies [99, 125], subcutaneous drainage significantly decreased incidence of 
postoperative wound dehiscence after Karydakis flap. In contrast, Colak et al. [109] found that drainage placement was associated with a two-fold increase in wound complication rate after Limberg flap. A meta-analysis by Milone [126] failed to clear the matter either.

\section{Summary and recommendations}

Due to a lack of reliable evidence, a formal recommendation on postoperative subcutaneous drainages could not be given.

Level of evidence: low

Consensus strength: strong consensus

\section{Postoperative prophylaxis of recurrent disease}

Although popular for decades, the efficacy of postoperative shaving has been questioned recently [127]. Moreover, sharpended rootless hairs have been found in sinus cavities of patients [128], commonly, shortly after haircut [129]. Thus, a permanent depilation by laser or depilation cream instead of shaving might be, at least theoretically, the preferred method for recurrence prophylaxis. Some recent case series reported on improved postoperative recurrence rates after pilonidal surgery when postoperative laser depilation was used [130-132]. However, in a prospective randomized study by Demircan [133], patients undergoing postoperative laser depilation after Karydakis flap demonstrated a significantly increased risk of disease recurrence. In a systematic review, Pronk et al. [134] showed a slightly decreased postoperative recurrence rate when laser depilation has been used after surgery. However, the evidence was not strong enough to make definite conclusions.

\section{Summary and recommendations}

Due to a lack of reliable data, a formal recommendation on use of postoperative laser depilation could not be given. Laser depilation could be considered individually as recurrence prophylaxis in young patients with a positive family history presenting with recurrent disease.

Level of evidence: low

Consensus strength: consensus

\section{Comments}

Three national Guidelines have been published as for today: the Italian [135], the American [136], and the present German National Guideline. Unfortunately, some contrasting conclusions could be found there.

\section{Open healing}

An increasingly critical view on open healing is expressed by German and Italian Guidelines. Impaired quality of life, prolonged, and expensive wound treatment and, furthermore, considerable time off-work are recognized as major disadvantages as compared with wound closure. However, American Guideline puts it on surgeons' and patients' preference whether to use open healing, marsupialization, or off-midline procedures. The latter methods were criticized for their requirement of "particular experience, skills and comfort with flapbased procedures." Also, marsupialization seems to be quite popular in the USA, whereas Italian authors did not mention and German Guideline completely refused this method.

\section{Wound closure}

A unanimous abandonment of midline wound closure can be found in all three Guidelines because of high incidence of wound breakdown and an increased recurrence rate. As a consequence, all authors recommended off-midline procedures as preferred methods to close the wound. Nevertheless, all three Guidelines are still hesitant to recommend off-midline procedures instead of open healing. The American Guideline advocates off-midline procedures "in the setting of complex and recurrent chronic pilonidal disease," whereas Italian Guideline suggests to perform off-midline surgery in "hirsute patients with extensive primary disease and deep natal clefts or with recurrent disease or unhealed midline wounds." Finally, the present German Guideline recommends Karydakis flap, Limberg flap, or Cleft lift when off-midline procedures are proposed; however, it still does not advocate their usage instead of open healing. Thus, some level of unease to recommend off-midline surgery in every patient undergoing excision of the pilonidal disease is still palpable probably because of apparent difficulties to learn those techniques by most general surgeons.

\section{Minimally invasive procedure}

Phenol treatment and fibrin glue are considered as reliable treatment options in patients with minimal disease in American and Italian Guideline, whereas both are clearly abandoned in German Guideline. There is extensive discussion on other techniques (Pit picking, Lord procedure, Gips technique, endoscopic surgery) in German Guideline and not quite as extensive in Italian. Surprisingly, American Guideline only considers endoscopic treatment as valuable minimally invasive procedure although the need for special experience and equipment are viewed as drawbacks. Despite those discrepancies, minimally invasive techniques are given full consideration as treatment option in patients with limited disease in all three publications. 


\section{Acute abscesses}

All three Guidelines recommend paramedian incision in presence of acute abscess postponing definitive treatment after resolution of inflammation.

\section{Elimination of hair}

Postoperative shaving was considered as standard of pilonidal disease therapy for many decades. Shaving or laser depilation is proposed as primary treatment or as (postoperative) adjunct to other procedures by Italian and American authors but not by
German although postoperative shaving is still very popular among German surgeons. Moreover, the present German Guideline warns on potentially increased recurrence risk when shaving is used postoperatively.

In conclusion, clear dynamics towards widespread use of minimally invasive techniques and off-midline procedures are recognizable in all international Guidelines. However, adherence to particular local traditions and principles of treatment incongruent with the new standards can still be clearly observed

\section{Appendix}

\section{Summary of recommendations as compared with previous version of the Guideline [1]}

\begin{tabular}{|c|c|c|}
\hline Subject & Recommendation & Comment \\
\hline Asymptomatic disease & No treatment necessary & Unchanged to previous version \\
\hline Acute abscess & Incision + drainage & Unchanged to previous version \\
\hline Phenol treatment & Favorable results. However, prohibited in Germany & Unchanged to previous version \\
\hline Pit picking and similar procedures & $\begin{array}{l}\text { Should be used in minor primary disease. Lack of reliable } \\
\text { long-term results }\end{array}$ & Unchanged to previous version \\
\hline Sinusectomy & Can be used in primary disease & Unchanged to previous version \\
\hline Laying-open procedure & No formal recommendation & New in the Guideline \\
\hline Endoscopic treatment & No formal recommendation & New in the Guideline \\
\hline Laser treatment & No formal recommendation & New in the Guideline \\
\hline Excision + open wound healing & $\begin{array}{l}\text { Excision should stay as limited as possible. Main drawbacks } \\
\text { are prolonged wound healing, time out of work and an increased } \\
\text { recurrence rate as compared with off-midline procedures }\end{array}$ & $\begin{array}{l}\text { As compared with previous version, } \\
\text { open healing is not named "standard } \\
\text { procedure for treatment of pilonidal } \\
\text { disease" anymore. }\end{array}$ \\
\hline Excision + marsupialization & No formal recommendation & Unchanged to previous version \\
\hline Midline closure & $\begin{array}{l}\text { Should not be used due to high incidence of wound dehiscence } \\
\text { and an increased recurrence rate. }\end{array}$ & Unchanged to previous version \\
\hline $\begin{array}{l}\text { Z-plasty, V-Y plasty, Dufourmentel } \\
\text { procedure }\end{array}$ & $\begin{array}{l}\text { Rarely used off-midline procedures play only a limited role } \\
\text { in Germany. Thus, they cannot be recommended. }\end{array}$ & $\begin{array}{l}\text { Compared with previous version, } \\
\text { rather dismissive recommendation }\end{array}$ \\
\hline Karydakis flap & $\begin{array}{l}\text { Karydakis flap should be considered as one of preferred } \\
\text { off-midline procedures. }\end{array}$ & Unchanged to previous version \\
\hline Cleft lift procedure & $\begin{array}{l}\text { Should be considered as one of preferred off-midline procedures. } \\
\text { Main drawbacks of the procedure are difficulties to understand } \\
\text { the marking and a trend towards an increased rate of wound } \\
\text { complications. }\end{array}$ & $\begin{array}{l}\text { Unchanged to previous version except } \\
\text { for somewhat more critical appraisal } \\
\text { of difficulties to learn the procedure }\end{array}$ \\
\hline Limberg flap & $\begin{array}{l}\text { Should be considered as one of preferred off-midline procedures. } \\
\text { The modified technique should be used instead of the original one. }\end{array}$ & Unchanged to previous version \\
\hline Fibrin glue & No formal recommendation & New in the Guideline \\
\hline Autologous tissue treatment & No formal recommendation & New in the Guideline \\
\hline Postoperative drainage use & $\begin{array}{l}\text { Due to a lack of reliable evidence, a formal recommendation } \\
\text { on postoperative subcutaneous drainages could not be given. }\end{array}$ & Unchanged to previous version \\
\hline Prophylaxis of recurrent disease & $\begin{array}{l}\text { A formal recommendation on the use of postoperative laser depilation } \\
\text { could not be given. Laser depilation could be considered individually } \\
\text { as recurrence prophylaxis in young patients with a positive family } \\
\text { history presenting with recurrent disease. }\end{array}$ & New in the Guideline \\
\hline
\end{tabular}


Authors' contributions I. Iesalnieks: Study conception and design, acquisition of data, analysis and interpretation of data, and drafting of manuscript. A. Ommer: Study conception and design, acquisition of data, analysis and interpretation of data, and critical revision of manuscript. A. Herold: Critical revision of manuscript. D. Doll: Study conception and design, acquisition of data, analysis and interpretation of data, and critical revision of manuscript.

\section{Compliance with ethical standards}

Conflict of interest The authors declare that they have no conflict of interest.

\section{References}

1. Iesalnieks I, Ommer A, Petersen S, Doll D, Herold A (2016) German national guideline on the management of pilonidal disease. Langenbeck's Arch Surg 401:599-609

2. Phillips, B, Ball C, Sackett D, Badenoch D, Straus S, Haynes B, Dawes M (2009) Oxford Centre for evidence-based medicine levels of evidence. https://www.cebm.ox.ac.uk/resources/levelsof-evidence

3. Atkins D, Best D, Briss PA, Eccles M, et al; GRADE Working Group (2004) Grading quality of evidence and strength of recommendations. BMJ 328:1490

4. Ommer A, Iesalnieks I, Doll D (2020) S3-Leitlinie: Sinus pilonidalis. 2. revidierte Fassung 2020. Coloproctology https:// doi.org/10.1007/s00053-020-00488-z

5. Doll D, Friederichs J, Boulesteix AL, Düsel W, Fend F, Petersen S (2008) Surgery for asymptomatic pilonidal sinus disease. Int J Color Dis 23:839-844

6. Doll D, Friederichs J, Dettmann H, Boulesteix AL, Düsel W, Petersen S (2008) Time and rate of sinus formation in pilonidal sinus disease. Int J Color Dis 23:359-364

7. Hussain ZI, Aghahoseini A, Alexander D (2012) Converting emergency pilonidal abscess into an elective procedure. Dis Colon Rectum 55:640-645

8. Khalil PN, Brand D, Siebeck M, Hallfeldt K, Mutschler W, Kanz KG (2009) Aspiration and injection-based technique for incision and drainage of a sacrococcygeal pilonidal abscess. J Emerg Med 36:60-63

9. Jensen SL, Harling H (1988) Prognosis after simple incision and drainage for a first-episode acute pilonidal abscess. Br J Surg 75: 60-61

10. Dogru O, Camci C, Aygen E, Girgin M, Topuz O (2004) Pilonidal sinus treated with crystallized phenol: an eight-year experience. Dis Colon Rectum 47:1934-1938

11. Kaymakcioglu N, Yagci G, Simsek A, Unlu A, Tekin OF, Cetiner S, Tufan T (2005) Treatment of pilonidal sinus by phenol application and factors affecting the recurrence. Tech Coloproctol 9: $21-24$

12. Olmez A, Kayaalp C, Aydin C (2013) Treatment of pilonidal disease by combination of pit excision and phenol application. Tech Coloproctol 17:201-206

13. Aksoy HM, Aksoy B, Egemen D (2010) Effectiveness of topical use of natural polyphenols for the treatment of sacrococcygeal pilonidal sinus disease: a retrospective study including 192 patients. Eur J Dermatol 20:476-481

14. Aygen E, Arslan K, Dogru O, Basbug M, Camci C (2010) Crystallized phenol in nonoperative treatment of previously operated, recurrent pilonidal disease. Dis Colon Rectum 53:932-935
15. Kayaalp C, Olmez A, Aydin C, Piskin T, Kahraman L (2010) Investigation of a one-time phenol application for pilonidal disease. Med Princ Pract 19:212-215

16. Kelly SB, Graham WJ (1989) Treatment of pilonidal sinus by phenol injection. Ulster Med J 58:56-59

17. Sakçak I, Avşar FM, Coşgun E (2010) Comparison of the application of low concentration and $80 \%$ phenol solution in pilonidal sinus disease. JRSM Short Rep 1:5

18. Calikoglu I, Gulpinar K, Oztuna D, Elhan AH, Dogru O, Akyol C, Erkek B, Kuzu MA (2017) Phenol injection versus excision with open healing in pilonidal disease: a prospective randomized trial. Dis Colon Rectum 60:161-169

19. Bruce RM, Santodonato J, Neal MW (1987) Summary review of the health effects associated with phenol. Toxicol Ind Health 3: 535-568

20. Lord PH, Millar DM (1965) Pilonidal sinus: a simple treatment. Br J Surg 52:298-300

21. Bascom J (1980) Pilonidal disease: origin from follicles of hairs and results of follicle removal as treatment. Surgery 87:567-572

22. Nordon IM, Senapati A, Cripps NP (2009) A prospective randomized controlled trial of simple Bascom's technique versus Bascom's cleft closure for the treatment of chronic pilonidal disease. Am J Surg 197:189-192

23. Iesalnieks I, Deimel S, Kienle K, Schlitt HJ, Zülke C (2011) Pitpicking surgery for pilonidal disease. Chirurg 82:927-931

24. Gips M, Melki Y, Salem L, Weil R, Sulkes J (2008) Minimal surgery for pilonidal disease using trephines: description of a new technique and long-term outcomes in 1,358 patients. Dis Colon Rectum 51:1656-1662

25. Khodakaram K, Stark J, Hoglund I et al (2017) Minimal excision and primary suture is a cost-efficient definitive treatment for pilonidal disease with low morbidity: a population-based interventional and a cross-sectional cohort study. World J Surg 41:1295-1302

26. Soll C, Hahnloser D, Dindo D, Clavien PA, Hetzer F (2008) A novel approach for treatment of sacrococcygeal pilonidal sinus: less is more. Int J Color Dis 23:177-180

27. Soll C, Dindo D, Steinemann D, Hauffe T, Clavien PA, Hahnloser D (2012) Sinusectomy for primary pilonidal sinus: less is more. Surgery 150:996-1001

28. Kement M, Oncel M, Kurt N, Kaptanoglu L (2006) Sinus excision for the treatment of limited chronic pilonidal disease: results after a medium-term follow-up. Dis Colon Rectum 49:1758-1762

29. Oncel M, Kurt N, Kement M, Colak E, Eser M, Uzun H (2002) Excision and marsupialization versus sinus excision for the treatment of limited chronic pilonidal disease: a prospective, randomized trial. Tech Coloproctol 6:165-169

30. Ortiz HH, Marti J, Sitges A (1977) Pilonidal sinus: a claim for simple track incision. Dis Colon Rectum 20:325-328

31. Mohamed HA, Kadry I, Adly S (2005) Comparison between three therapeutic modalities for non-complicated pilonidal sinus disease. Surgeon 3:73-77

32. Garg P, Menon GR, Gupta V (2016) Laying open (deroofing) and curettage of sinus as treatment of pilonidal disease: a systematic review and meta-analysis. ANZ J Surg 86:27-33

33. Chia CL, Tay VW, Mantoo SK (2015) Endoscopic pilonidal sinus treatment in the Asian population. Surg Laparosc Endosc Percutan Tech 25:e95-e97

34. Giarratano G, Toscana C, Shalaby M, Buonomo O, Petrella G, Sileri P (2017) Endoscopic pilonidal sinus treatment: long-term results of a prospective series. JSLS 21:e2017.00043

35. Meinero P, La Torre M, Lisi G et al (2019) Endoscopic pilonidal sinus treatment (EPSiT) in recurrent pilonidal disease: a prospective international multicenter study. Int J Color Dis 34:741-746

36. Meinero P, Stazi A, Carbone A, Fasolini F, Regusci L, la Torre M (2016) Endoscopic pilonidal sinus treatment: a prospective multicentre trial. Color Dis 18:O164-O170 
37. Milone M, Fernandez LM, Musella M et al (2016) Safety and efficacy of minimally invasive video-assisted ablation of pilonidal sinus: a randomized clinical trial. JAMA Surg 151:547-553

38. Emile SH, Elfeki H, Shalaby M, Sakr A, Giaccaglia V, Sileri P, Wexner SD (2018) Endoscopic pilonidal sinus treatment: a systematic review and meta-analysis. Surg Endosc 32(9):3754-3762

39. Tien T, Athem R, Arulampalam T (2018) Outcomes of endoscopic pilonidal sinus treatment (EPSiT): a systematic review. Tech Coloproctol 22:325-331

40. Georgiou GK (2018) Outpatient laser treatment of primary pilonidal disease: the PiLaT technique. Tech Coloproctol 22:773-778

41. Pappas AF, Christodoulou DK (2018) A new minimally invasive treatment of pilonidal sinus disease with the use of a diode laser: a prospective large series of patients. Color Dis 20:O207-O214

42. Al-Homoud SJ, Habib ZS, Abdul Jabbar AS, Isbister WH (2001) Management of sacrococcygeal pilonidal disease. Saudi Med J 22: 762-764

43. Fazeli MS, Lebaschi AH, Adel MG, Kazemeini AR (2008) Evaluation of the outcome of complete sinus excision with reconstruction of the umbilicus in patients with umbilical pilonidal sinus. World J Surg 32:2305-2308

44. Füzün M, Bakir H, Soylu M, Tansuğ T, Kaymak E, Haŕmancioğlu O (1994) Which technique for treatment of pilonidal sinus - open or closed? Dis Colon Rectum 37:1148-1150

45. McCallum IJ, King PM, Bruce J (2008) Healing by primary closure versus open healing after surgery for pilonidal sinus: systematic review and meta-analysis. BMJ 336:868-871

46. Reboa G, Gipponi M, Testa T, Giannini G, Scala M, Dalla Costa $R$, Strada P (2007) Regenerative medicine for the definitive surgical repair of pilonidal sinus. A new method of wound reconstruction. In Vivo 21:529-534

47. Søndenaa K, Andersen E, Søreide JA (1992) Morbidity and short term results in a randomised trial of open compared with closed treatment of chronic pilonidal sinus. Eur J Surg 158:351-355

48. Testini M, Piccinni G, Miniello S, Di Venere B, Lissidini G, Nicolardi V, Bonomo GM (2001) Treatment of chronic pilonidal sinus with local anaesthesia: a randomized trial of closed compared with open technique. Color Dis 3:427-430

49. Al-Hassan HK, Francis IM, Neglén P (1990) Primary closure or secondary granulation after excision of pilonidal sinus? Acta Chir Scand 156:695-699

50. Gendy AS, Glick RD, Hong AR, Dolgin SE, Soffer SZ, Landers H, Herrforth M, Rosen NG (2011) A comparison of the cleft lift procedure vs wide excision and packing for the treatment of pilonidal disease in adolescents. J Pediatr Surg 46:1256-1259

51. Gidwani AL, Murugan K, Nasir A, Brown R (2010) Incise and lay open: an effective procedure for coccygeal pilonidal sinus disease. Ir J Med Sci 179:207-210

52. Iesalnieks I, Agha A, von Breitenbuch P, Schlitt HJ, Fürst A (2006) Chirurgische Behandlung des Sinus pilonidalis. Viszeralchirurgie 41:399-406

53. Jamal A, Shamim M, Hashmi F, Qureshi MI (2009) Open excision with secondary healing versus rhomboid excision with Limberg transposition flap in the management of sacrococcygeal pilonidal disease. J Pak Med Assoc 59:157-160

54. Matter I, Kunin J, Schein M, Eldar S (1995) Total excision versus non-resectional methods in the treatment of acute and chronic pilonidal disease. Br J Surg 82:752-753

55. Rabie ME, Al Refeidi AA, Al Haizaee A, Hilal S, Al Ajmi H, Al Amri AA (2007) Sacrococcygeal pilonidal disease: sinotomy versus excisional surgery, a retrospective study. ANZ J Surg 77:177180

56. Solla JA, Rothenberger DA (1990) Chronic pilonidal disease. An assessment of 150 cases. Dis Colon Rectum 33:758-761

57. Stansby G, Greatorex R (1989) Phenol treatment of pilonidal sinuses of the natal cleft. Br J Surg 76:729-730
58. Doll D (2007) Sinotomy versus excisional surgery for pilonidal sinus. ANZ J Surg 77:599-600 author reply 600

59. Iesalnieks I, Fürst A, Rentsch M, Jauch KW (2003) Primary midline closure after excision of a pilonidal sinus is associated with a high recurrence rate. Chirurg. 74(5):461-468

60. Käser SA, Zengaffinen R, Uhlmann M, Glaser C, Maurer CA (2015) Primary wound closure with a Limberg flap vs. secondary wound healing after excision of a pilonidal sinus: a multicentre randomised controlled study. Int J Color Dis 30:97-103

61. Al-Salamah SM, Hussain MI, Mirza SM (2007) Excision with or without primary closure for pilonidal sinus disease. J Pak Med Assoc 57:388-391

62. Kronborg O, Christensen K, Zimmermann-Nielsen C (1985) Chronic pilonidal disease: a randomized trial with a complete 3year follow-up. Br J Surg 72:303-304

63. Lorant T, Ribbe I, Mahteme H, Gustafsson UM, Graf W (2011) Sinus excision and primary closure versus laying open in pilonidal disease: a prospective randomized trial. Dis Colon Rectum 54: 300-305

64. Al-Khamis A, McCallum I, King PM, Bruce J (2011) Healing by primary versus secondary intention after surgical treatment for pilonidal sinus. Cochrane Database Syst Rev:CD006213

65. Stauffer VK, Luedi MM, Kauf P, Schmid M, Diekmann M, Wieferich K, Schnüriger B, Doll D (2018) Common surgical procedures in pilonidal sinus disease: a meta-analysis, merged data analysis, and comprehensive study on recurrence. Sci Rep 8:3058

66. Meban S, Hunter E (1982) Outpatient treatment of pilonidal disease. Can Med Assoc J 126:941

67. Watters N, Macdonald IB (1958) Marsupialization of pilonidal sinus and abscess: a report of 50 cases. Can Med Assoc J 79: 236-240

68. Aydede H, Erhan Y, Sakarya A, Kumkumoglu Y (2001) Comparison of three methods in surgical treatment of pilonidal disease. ANZ J Surg 71:362-364

69. Doll D, Luedi MM, Evers T, Kauf P, Matevossian E (2015) Recurrence-free survival, but not surgical therapy per se, determines 583 patients' long-term satisfaction following primary pilonidal sinus surgery. Int J Color Dis 30:605-611

70. Abu Galala KH, Salam IM, Abu Samaan KR, El Ashaal YI, Chandran VP, Sabastian M, Sim AJ (1999) Treatment of pilonidal sinus by primary closure with a transposed rhomboid flap compared with deep suturing: a prospective randomised clinical trial. Eur J Surg 165:468-472

71. Baier PK, Baumgartner U, Furtwängler A, Holzinger F, Schöffel U (2002) Therapy of the pilonidal sinus - primary wound closure or open wound after excision. Zentralbl Chir 127:310-314

72. Brieler HS (1997) Infected pilonidal sinus. Langenbecks Arch Chir Suppl Kongressbd 114:497-500

73. Denkers D, Girona J (1996) Der abszedierte Sinus pilonidalis der Steißbeinregion - Möglichkeiten der chirurgischen Versorgung. Coloproctology 18:257-259

74. Doll D, Evers T, Matevossian E, Petersen S (2009) Outcome of chronic pilonidal disease treatment after ambulatory plain midline excision and primary suture. Am J Surg 197:693-694

75. Dudink R, Veldkamp J, Nienhuijs S, Heemskerk J (2011) Secondary healing versus midline closure and modified Bascom natal cleft lift for pilonidal sinus disease. Scand J Surg 100:110 113

76. Holmebakk T, Nesbakken A (2005) Surgery for pilonidal disease. Scand J Surg 94:43-46

77. Lee SL, Tejirian T, Abbas MA (2008) Current management of adolescent pilonidal disease. J Pediatr Surg 43:1124-1127

78. Muzi MG, Milito G, Cadeddu F, Nigro C, Andreoli F, Amabile D, Farinon AM (2010) Randomized comparison of Limberg flap versus modified primary closure for the treatment of pilonidal disease. Am J Surg 200:9-14 
79. Muzi MG, Milito G, Nigro C, Cadeddu F, Farinon AM (2009) A modification of primary closure for the treatment of pilonidal disease in day-care setting. Color Dis 11:84-88

80. Nursal TZ, Ezer A, Caliş̧kan K, Törer N, Belli S, Moray G (2010) Prospective randomized controlled trial comparing V-Y advancement flap with primary suture methods in pilonidal disease. Am J Surg 199:170-177

81. Tavassoli A, Noorshafiee S, Nazarzadeh R (2011) Comparison of excision with primary repair versus Limberg flap. Int J Surg 9: 343-346

82. Akca T, Colak T, Ustunsoy B, Kanik A, Aydin S (2005) Randomized clinical trial comparing primary closure with the Limberg flap in the treatment of primary sacrococcygeal pilonidal disease. Br J Surg 92:1081-1084

83. Okuş A, Sevinç B, Karahan O, Eryilmaz MA (2012) Comparison of Limberg flap and tension-free primary closure during pilonidal sinus surgery. World J Surg 36:431-435

84. Zimmerman CE (1978) Outpatient excision and primary closure of pilonidal cysts and sinuses. Am J Surg 136:640-642

85. Sevinc B, Karahan O, Okus A et al (2016) Randomized prospective comparison of midline and off-midline closure techniques in pilonidal sinus surgery. Surgery 159:749-754

86. Youssef AT, El-Awady S, Farid M (2015) Tension-free primary closure compared with modified Limberg flap for pilonidal sinus disease. A prospective balanced randomized study. Egypt J Surg 34:85-89

87. Neșşar G, Kayaalp C, Seven C (2004) Elliptical rotation flap for pilonidal sinus. Am J Surg 187:300-303

88. Eryilmaz R, Okan I, Coskun A, Bas G, Sahin M (2009) Surgical treatment of complicated pilonidal sinus with a fasciocutaneous $\mathrm{V}$ Y advancement flap. Dis Colon Rectum 52:2036-2040

89. Gwynn BR (1986) Use of the rhomboid flap in pilonidal sinus. Ann R Coll Surg Engl 68:40-41

90. Sharma PP (2006) Multiple Z-plasty in pilonidal sinus-a new technique under local anesthesia. World J Surg 30:2261-2265

91. Lieto E, Castellano P, Pinto M, Zamboli A, Pignatelli C, Galizia G (2010) Dufourmentel rhomboid flap in the radical treatment of primary and recurrent sacrococcygeal pilonidal disease. Dis Colon Rectum 53:1061-1068

92. Quinodoz PD, Chilcott M, Grolleau JL, Chavoin JP, Costagliola M (1999) Surgical treatment of sacrococcygeal pilonidal sinus disease by excision and skin flaps: the Toulouse experience. Eur J Surg 165:1061-1065

93. Akinci OF, Coskun A, Ozgonul A et al (2006) Surgical treatment of complicated pilonidal disease: limited separate elliptical excision with primary closure. Color Dis 8:704-709

94. Bessa SS (2007) Results of the lateral advancing flap operation (modified Karydakis procedure) for the management of pilonidal sinus disease. Dis Colon Rectum 50:1935-1940

95. Bessa SS (2013) Comparison of short-term results between the modified Karydakis flap and the modified Limberg flap in the management of pilonidal sinus disease: a randomized controlled study. Dis Colon Rectum 56:491-498

96. Kitchen PR (1996) Pilonidal sinus: experience with the Karydakis flap. Br J Surg 83:1452-1455

97. Moran DC, Kavanagh DO, Adhmed I, Regan MC (2011) Excision and primary closure using the Karydakis flap for the treatment of pilonidal disease: outcomes from a single institution. World J Surg 35:1803-1808

98. Morden P, Drongowski RA, Geiger JD, Hirschl RB, Teitelbaum DH (2005) Comparison of Karydakis versus midline excision for treatment of pilonidal sinus disease. Pediatr Surg Int 21:793-796

99. Sözen S, Emir S, Guzel K et al (2011) Are postoperative drains necessary with the Karydakis flap for treatment of pilonidal sinus? (Can fibrin glue be replaced to drains?) A prospective randomized trial. Ir J Med Sci 180:479-482
100. Prassas D, Rolfs TM, Schumacher FJ, Krieg A (2018) Karydakis flap reconstruction versus Limberg flap transposition for pilonidal sinus disease: a meta-analysis of randomized controlled trials. Langenbeck's Arch Surg 403:547-554

101. Sahebally SM, McMahon G, Walsh SR, Burke JP (2019) Classical Limberg versus classical Karydakis flaps for pilonidal disease- an updated systematic review and meta-analysis of randomized controlled trials. Surgeon. 17(5):300-308

102. Bascom JU (1987) Repeat pilonidal operations. Am J Surg 154: $118-122$

103. Bascom J, Bascom T (2002) Failed pilonidal surgery: new paradigm and new operation leading to cures. Arch Surg 137:11461150 discussion 1151

104. Karydakis GE (1992) Easy and successful treatment of pilonidal sinus after explanation of its causative process. Aust N Z J Surg 62:385-389

105. Altinli E, Koksal N, Onur E, Celik A, Sumer A (2007) Impact of fibrin sealant on Limberg flap technique: results of a randomized controlled trial. Tech Coloproctol 11:22-25

106. Arslan K, Said Kokcam S, Koksal H, Turan E, Atay A, Dogru O (2014) Which flap method should be preferred for the treatment of pilonidal sinus? A prospective randomized study. Tech Coloproctol 18:29-37

107. Cihan A, Mentes BB, Tatlicioglu E, Ozmen S, Leventoglu S, Ucan BH (2004) Modified Limberg flap reconstruction compares favourably with primary repair for pilonidal sinus surgery. ANZ J Surg 74:238-242

108. Cihan A, Ucan BH, Comert M, Cesur A, Cakmak GK, Tascilar O (2006) Superiority of asymmetric modified Limberg flap for surgical treatment of pilonidal disease. Dis Colon Rectum 49:244 249

109. Colak T, Turkmenoglu O, Dag A, Akca T, Aydin S (2010) A randomized clinical study evaluating the need for drainage after Limberg flap for pilonidal sinus. J Surg Res 158:127-131

110. Ersoy E, Devay AO, Aktimur R, Doganay B, Özdoğan M, Gündoğdu RH (2009) Comparison of the short-term results after Limberg and Karydakis procedures for pilonidal disease: randomized prospective analysis of 100 patients. Color Dis 11:705-710

111. Ertan T, Koc M, Gocmen E, Aslar AK, Keskek M, Kilic M (2005) Does technique alter quality of life after pilonidal sinus surgery? Am J Surg 190:388-392

112. Guner A, Boz A, Ozkan OF et al (2013) Limberg flap versus Bascom cleft lift techniques for sacrococcygeal pilonidal sinus: prospective, randomized trial. World J Surg 37:2074-2080

113. Kirkil C, Boyuk A, Bulbuller N et al (2011) The effects of drainage on the rates of early wound complications and recurrences after Limberg flap reconstruction in patients with pilonidal disease. Tech Coloproctol 15:425-429

114. Okus A, Sevinc B, Karahan O et al (2012) Comparison of Limberg flap and tension-free primary closure during pilonidal sinus surgery. World J Surg 36:431-435

115. Tekin A (2005) A simple modification with the Limberg flap for chronic pilonidal disease. Surgery 138:951-953

116. Karakayali F, Karagulle E, Karabulut Z, Oksuz E, Moray G, Haberal M (2009) Unroofing and marsupialization vs. rhomboid excision and Limberg flap in pilonidal disease: a prospective, randomized, clinical trial. Dis Colon Rectum 52:496-502

117. Enriquez-Navascues JM, Emparanza JI, Alkorta M, Placer C (2014) Meta-analysis of randomized controlled trials comparing different techniques with primary closure for chronic pilonidal sinus. Tech Coloproctol 18:863-872

118. Boshnaq M, Phan YC, Martini I, Harilingam M, Akhtar M, Tsavellas G (2018) Limberg flap in management of pilonidal sinus disease: systematic review and a local experience. Acta Chir Belg 118:78-84 
119. Greenberg R, Kashtan H, Skornik Y, Werbin N (2004) Treatment of pilonidal sinus disease using fibrin glue as a sealant. Tech Coloproctol 8:95-98

120. Lund JN, Leveson SH (2005) Fibrin glue in the treatment of pilonidal sinus: results of a pilot study. Dis Colon Rectum 48:1094 1096

121. Seleem MI, Al-Hashemy AM (2005) Management of pilonidal sinus using fibrin glue: a new concept and preliminary experience. Color Dis 7:319-322

122. Sian TS, Herrod PJJ, Blackwell JEM, Hardy EJO, Lund JN (2018) Fibrin glue is a quick and effective treatment for primary and recurrent pilonidal sinus disease. Tech Coloproctol 22:779-784

123. Gipponi M, Reboa G, Testa T, Giannini G, Strada P (2010) Tension-free primary closure with autologous platelet gel versus Vivostat- for the definitive treatment of chronic sacrococcygeal pilonidal disease. In Vivo 24:583-589

124. Spyridakis M, Christodoulidis G, Chatzitheofilou C, Symeonidis D, Tepetes K (2009) The role of the platelet-rich plasma in accelerating the wound-healing process and recovery in patients being operated for pilonidal sinus disease: preliminary results. World J Surg 33:1764-1769

125. Gürer A, Gomceli I, Ozdogan M et al (2005) Is routine cavity drainage necessary in Karydakis flap operation? A prospective, randomized trial. Dis Colon Rectum 48:1797-1799

126. Milone M, Di Minno MN, Musella M et al (2013) The role of drainage after excision and primary closure of pilonidal sinus: a meta-analysis. Tech Coloproctol 17:625-630

127. Petersen S, Wietelmann K, Evers T, Hüser N, Matevossian E, Doll D (2009) Long-term effects of postoperative razor epilation in pilonidal sinus disease. Dis Colon Rectum 52:131-134

128. Bosche F, Luedi MM, van der Zypen D, Moersdorf P, Krapohl B, Doll D (2018) The hair in the sinus: sharp-ended rootless head hair fragments can be found in large amounts in pilonidal sinus nests. World J Surg 42:567-573
129. Doll D, Maier K, Albers K et al (2019) Another common sharp hair fragment disease - barbers anterior disease (BAD). Pilonidal Sinus J 5:1-15

130. Conroy FJ, Kandamany N, Mahaffey PJ (2008) Laser depilation and hygiene: preventing recurrent pilonidal sinus disease. J Plast Reconstr Aesthet Surg 61:1069-1072

131. Ganjoo A (2011) Laser hair reduction for pilonidal sinus - my experience. J Cutan Aesthet Surg 4:196

132. Oram Y, Kahraman F, Karincaoglu Y et al (2010) Evaluation of 60 patients with pilonidal sinus treated with laser epilation after surgery. Dermatol Surg 36:88-91

133. Demircan F, Akbulut S, Yavuz R et al (2015) The effect of laser epilation on recurrence and satisfaction in patients with sacrococcygeal pilonidal disease: a prospective randomized controlled trial. Int J Clin Exp Med 8:2929-2933

134. Pronk AA, Eppink L, Smakman N, Furnee EJB (2018) The effect of hair removal after surgery for sacrococcygeal pilonidal sinus disease: a systematic review of the literature. Tech Coloproctol 22: $7-14$

135. Segre D, Pozzo M, Perinotti R, Roche B, Italian Society of Colorectal Surgery (2015) The treatment of pilonidal disease: guidelines of the Italian Society of Colorectal Surgery (SICCR). Tech Coloproctol 19:607-613

136. Johnson EK, Vogel JD, Cowan ML, Feingold DL, Steele SR, Clinical Practice Guidelines Committee of the American Society of Colon and Rectal Surgeons (2019) The American Society of Colon and Rectal Surgeons' clinical practice guidelines for the management of pilonidal disease. Dis Colon Rectum 62:146-157

Publisher's note Springer Nature remains neutral with regard to jurisdictional claims in published maps and institutional affiliations. 